\title{
Pseudo-acute Renal Failure due to Intraperitoneal Urine Leakage
}

\author{
Canxin Zhou ${ }^{1}$, Xuxia Ying ${ }^{2}$ and Weisheng Feng ${ }^{1}$
}

\begin{abstract}
Ascites, oliguria and vomiting with an increasing serum creatinine level are often observed in patients with acute renal failure. However, these symptoms are also noted in individuals with intraperitoneal urinary leakage. Bladder rupture without a history of obvious trauma is sometimes mistaken for acute renal failure. We herein report a case of bladder perforation resembling acute renal failure in which the presentation was delayed until the patient began to experience symptoms of urinary ascites. The diagnostic dilemma associated with the rarity of this condition and possible aetiologies are discussed.
\end{abstract}

Key words: ascites, oliguria, vomiting, acute renal failure, bladder perforation

(Intern Med 54: 1777-1780, 2015)

(DOI: 10.2169/internalmedicine.54.3330)

\section{Introduction}

Spontaneous or traumatic intraperitoneal bladder rupture is rare. The sudden onset of abdominal discomfort, ascites and oliguria associated with elevated renal parameters are clues to the diagnosis. However, there is sometimes a delay in diagnosis, as ascites, oliguria and an increasing serum creatinine level are also observed in patients with acute renal failure. This report describes a case of bladder perforation resembling acute renal failure. The diagnostic features, possible aetiologies and treatments for this condition are discussed below.

\section{Case Report}

A 34-year-old woman presented with a seven-day history of painless abdominal distension and oliguria with a threeday history of nausea and vomiting. No signs of fever, urinary tract dysfunction or digestive discomfort were reported. An abdominal examination revealed abdominal distension with shifting dullness and diffuse tenderness; no abdominal rebound tenderness was detected.

The patient had no history of kidney disease. Ultrasound showed a normal kidney size bilaterally, without evidence of hydronephrosis. In addition, laboratory investigations dem- onstrated elevated blood urea $(90.62 \mathrm{mg} / \mathrm{dL})$ and serum creatinine $(5.86 \mathrm{mg} / \mathrm{dL})$ levels, whereas the serum electrolyte and albumin levels were within the normal ranges. Although proteinuria was negative on a urinalysis, an emergency abdominal computerized tomography (CT) scan revealed large abdominal effusion and an enlarged uterus with an uneven density. Diagnostic aspiration of the ascites confirmed the presence of transudate. A diagnosis of spontaneous peritonitis was excluded based on the findings of a normal fluid cell count and negative culture results. The spot urine protein: creatinine ratio was $16.95 \mathrm{mg} / \mathrm{g}$ (normal range: $<30 \mathrm{mg} / \mathrm{g}$ ), and paracentesis yielded $4.8 \mathrm{~L}$ of straw-coloured peritoneal fluid.

A ureteral catheter was carefully inserted in the case that the enlarged uterus pressed upon on the ureter. Surprisingly, the abdominal distension began to resolve, which indicated the possibility of bladder perforation. However, the diagnosis of intra-abdominal urinary leakage was more likely, as biochemistry of the ascites disclosed a creatinine concentration of $33.15 \mathrm{mg} / \mathrm{dL}$, almost six times as high as the serum creatinine level, and an elevated ascites urea level of 211.01 $\mathrm{mg} / \mathrm{dL}$. The sodium, potassium and chloride levels in the ascites were $107,11.5$ and $80 \mathrm{mEq} / \mathrm{L}$, respectively, which differed markedly from the serum electrolyte levels (Table). A subsequent voiding cystourethrogram confirmed extravasation of the urine from a small site of rupture in the dome of

${ }^{1}$ Department of Nephrology, Yinzhou People's Hospital, China and ${ }^{2}$ Department of Critical Care Medicine, Yinzhou People's Hospital, China Received for publication May 21, 2014; Accepted for publication November 18, 2014

Correspondence to Dr. Canxin Zhou, zhoucanxin@126.com 
Table. Results of Biochemical Analysis of Blood and Peritoneal Fluid.

\begin{tabular}{|c|c|c|c|c|c|c|}
\hline & \multicolumn{2}{|c|}{$\begin{array}{l}\text { First day o } \\
\text { admission }\end{array}$} & \multicolumn{2}{|c|}{$\begin{array}{l}\text { Second } \\
\text { admission }\end{array}$} & \multicolumn{2}{|c|}{$\begin{array}{l}\text { Third day } \\
\text { admission }\end{array}$} \\
\hline & Blood & $\begin{array}{l}\text { Peritoneal } \\
\text { fluid }\end{array}$ & Blood & $\begin{array}{l}\text { Peritoneal } \\
\text { fluid }\end{array}$ & Blood & $\begin{array}{l}\text { Peritoneal } \\
\text { fluid }\end{array}$ \\
\hline $\begin{array}{l}\text { Sodium } \\
(\mathrm{mEq} / \mathrm{L})\end{array}$ & 136 & - & 135 & 107 & 133 & - \\
\hline $\begin{array}{l}\text { Chloride } \\
(\mathrm{mEq} / \mathrm{L})\end{array}$ & 97 & - & 96 & 80 & 105 & - \\
\hline $\begin{array}{l}\text { Potassium } \\
(\mathrm{mEq} / \mathrm{L})\end{array}$ & 4.0 & - & 3.7 & 11.05 & 3.7 & - \\
\hline $\begin{array}{l}\text { Creatinine } \\
(\mathrm{mg} / \mathrm{dL})\end{array}$ & 7.43 & - & 5.86 & 33.15 & 0.70 & - \\
\hline $\begin{array}{l}\text { Urea } \\
(\mathrm{mg} / \mathrm{dL})\end{array}$ & 92.75 & - & 90.62 & 211.01 & 21.10 & - \\
\hline
\end{tabular}

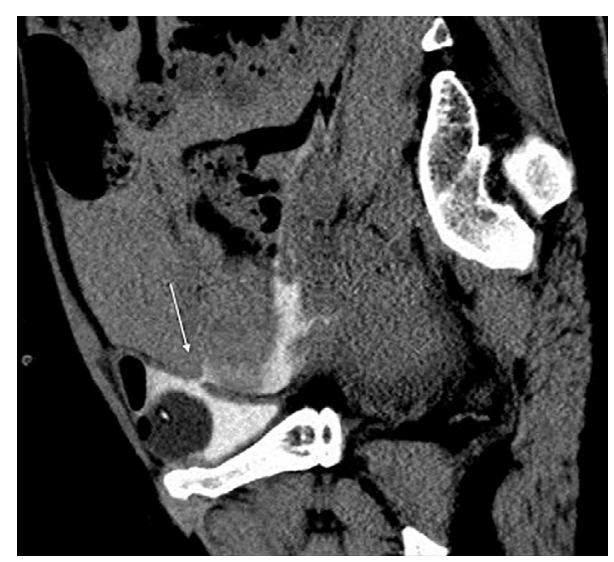

Figure 1. Voiding cystourethrogram showing the extravasation of contrast into peritoneal cavity from a small rupture on the dome of the bladder.

the bladder (Fig. 1, 2). The creatinine level rapidly decreased from 5.86 to $0.70 \mathrm{mg} / \mathrm{dL}$ one day after ureteral catheter insertion.

CT showed an enlarged uterus, and a gynecological examination demonstrated the size of the uterus to be as large as that observed in pregnant women at three and a half months. Spontaneous rupture of the bladder was therefore diagnosed as a consequence of the substantial pressure on the bladder caused by compression from the enlarged uterus. Hysterectomy was performed under the consultation with a gynecologist. Intraoperatively, a tear measuring almost one 1 $\mathrm{cm}$ in size in the bottom of the left bladder was detected and the size of the uterus was as large as that noted in pregnancy. We therefore carried out hysterectomy and bladder repair. The pathology showed adenomyosis, and the patient was discharged six days later.

\section{Discussion}

Urinary bladder rupture is an uncommon event, with a reported incidence of approximately 1 in 126,000 hospital admissions (1). Spontaneous rupture may be idiopathic or occur secondary to diseases involving the urinary bladder and/ or outflow. Previously reported cases of idiopathic spontaneous rupture of the urinary bladder have been due to the ef-

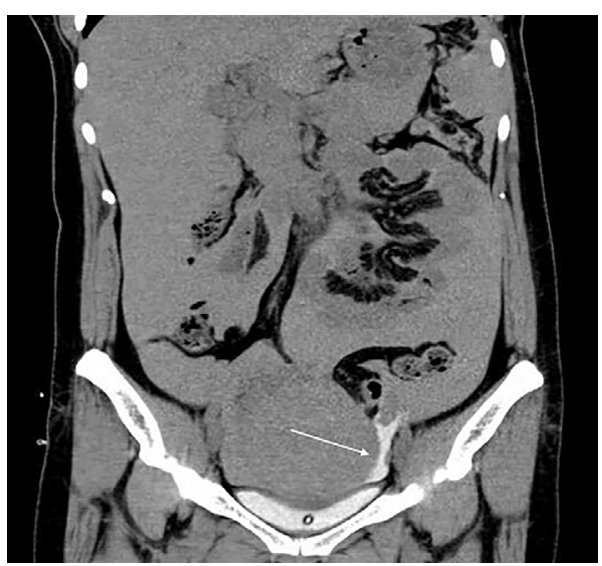

Figure 2. Voiding cystourethrogram showing leakage of contrast into peritoneal cavity from the left bladder.

fects of ongoing chronic diseases of the urinary bladder $(42 \%)$ or prolonged urinary retention $(35 \%)(1)$. In the available literature, this condition is predominantly associated with risk factors such as non-penetrating blunt trauma, neuropathic bladder, radiotherapy for pelvic malignancy, iatrogenic intraoperative injury, binge alcohol drinking, continuous bladder irrigation, a postpartum status, bladder diverticulum and pelvic organ prolapse (2-12). To our knowledge, however, there are no reports of urinary ascites resulting from an enlarged uterus due to adenomyosis inducing bladder compression.

According to the clinical data in this case, we considered the obstruction of the outlet of the bladder to be caused by the enlarged uterus as a result of adenomyosis leading to bladder compression, which subsequently resulted in the capacity of the bladder being greater and the wall of the bladder being much thinner. Sudden spontaneous rupture may occur in association with nausea or other factors causing increased intra-abdominal pressure, in which the urine travels into the abdominal cavity. This type of urinary bladder rupture, which results in the presence of urine in the peritoneal cavity, often presents with peritoneal and rebound tenderness in addition to abdominal pain. However, not all patients with peritonitis exhibit such symptoms. In the current case, we failed to diagnose the patient promptly, with a conse- 
quent delay in diagnosis and treatment, due to the lack of obvious symptoms of peritonitis or an apparent history of trauma.

Urinary leakage usually presents with signs of peritonitis $(7,13)$. Therefore, acute renal failure associated with massive ascites and peritonitis should be distinguished from urinary leakage. However, although the present patient had abdominal pain, no rebound tenderness, a sign of peritonitis, was noted. In this case, the patient experienced painless distension of the abdomen caused by ascites and demonstrated a late presentation to the hospital, which resulted in erroneous initial working diagnoses, including ascites due to possible liver disease. Nephrotic syndrome also was considered; however, this diagnosis was excluded, as no significant proteinuria was detected. Fortunately, an additional chemical analysis of the creatinine level in the ascites fluid helped us to obtain the correct diagnosis. Observations of the relief of abdominal pain and generalised distension following indwelling catheterisation should raise suspicion regarding the possibility of bladder rupture.

The sudden elevation of previously normal serum urea and creatinine levels is a key feature in the diagnosis of urinary ascites. The new onset of renal failure in such clinical cases is based on the concept of "reverse auto-dialysis" of the peritoneal membrane, a reverse form of continuous ambulatory peritoneal dialysis that is most apparent when the presentation is delayed, thus leading to diffusion of metabolic waste products into the dialysate. The peritoneum subsequently reabsorbs urea and creatinine from the leaked urine, which increases the serum levels of these compounds $(4,14)$.

Intraperitoneal urinary leakage is characterized by an increased serum creatinine level due to the reabsorption of creatinine in the urine via the peritoneal membrane, resulting in oliguria and ascites. Because the symptoms are often nonspecific, misdiagnosis is common $(8,13)$. Some patients may experience life-threatening complications $(15,16)$. Therefore, obtaining an early diagnosis is necessary in order to provide proper emergency treatment and thereby reduce the incidence of life-threatening complications and avoid unnecessary blood purification therapies.

The role of the creatinine level in ascites in helping clinicians to diagnose spontaneous bladder perforation has not been fully explored. A normal creatinine value in the peritoneal fluid is equivalent to a normal serum level and significantly less than the urinary level, and an ascites creatinine: serum creatinine ratio of $>1.0$ is highly suggestive of intraperitoneal urine leakage (17); our patient's ratio was 5.7.

Some authors have reported a correlation between the serum and ascites electrolyte levels, although this finding has not been clearly established (18-20). The sodium, potassium and chloride levels in ascites fluid are nearly identical to those in the serum. However, in the current case, the ascites sodium, potassium and chloride levels differed markedly from the corresponding serum levels. These differences were likely due to the effects of leakage of the urine into the ab- dominal cavity. Measuring the electrolyte levels in ascites may therefore be helpful for diagnosing intraperitoneal urinary leakage.

Bladder perforation may be confirmed on retrograde cystograms or CT urograms. In this case, we also diagnosed bladder rupture on retrograde angiography.

The definitive treatment for urinary leakage is surgery. However, ensuring adequate drainage of the urinary ascites fluid via paracentesis and the placement of a Foley catheter can help to improve the patient's symptoms and normalize the serum creatinine level. The serum creatinine level usually returns to normal within 48 hours $(2,5,6,13,14,16$, 17). Accordingly, the serum creatinine level in our patient quickly returned to normal following the insertion of a urinary catheter, and the ascites subsequently resolved.

In summary, we herein reported a case of intraperitoneal urinary leakage resembling acute kidney injury. In this case, the electrolyte levels in the ascites fluid differed markedly from the serum levels and the peritoneal creatinine level was higher than the corresponding serum level. Hence, patients presenting with an acutely rising serum creatinine level, recurrent ascites and oliguria should be assessed for intraperitoneal urine leakage by an internal medicine specialist.

\section{The authors state that they have no Conflict of Interest (COI).}

Canxin Zhou and Xuxia Ying contributed equally to this work.

\section{References}

1. Bastable JR, De Jode LR, Warren RP. Spontaneous rupture of the bladder. Br J Urol 31: 78-86, 1959.

2. Goto S, Yamadori M, Igaki N, Kim JI, Fukagawa M. Pseudoazotaemia due to intraperitoneal urine leakage: a report of two cases. NDT Plus 3: 474-476, 2010.

3. Sharma A, Teh B, Morgan DJR, Bell D, Woodhouse C. When ascites is not ascites. Postgrad Med J 84: 502-503, 2008.

4. Aber A, Hyder SA, Arumuham V. An unusual case of spontaneous bladder perforation with associated autodialysis of the ensuing urinary ascites. Case Rep Med 2011: 145084, 2011.

5. Ridinger HA, Kavitt RT, Green JK. Urinary ascites and renal failure from unrecognized bladder rupture. Am J Med 125: e1-e2, 2012.

6. Arunkumar K, Selvakumar E, Vimalraj V, Jeswanth S, Jyotibasu $\mathrm{D}$, Surendran R. An unusual case of urinary ascites presenting as postoperative acute oliguric renal failure. Trop Gastroenterol 34: 52-53, 2013.

7. Fujikawa K, Yamamichi F, Nonomura M, Soeda A, Takeuchi H. Spontaneous rupture of the urinary bladder is not a rare complication of radiotherapy for cervical cancer: report of six cases. Gynecol Oncol 73: 439-442, 1999.

8. Tai CK, Li SK, Hou SM, Fan CW. Bladder injury mimicking acute renal failure after cesarean section: a diagnostic challenge and minimally invasive management. Surg Laparosc Endosc Percutan Tech 18: 301-303, 2008.

9. Dooldeniya MD, Khafagy R, Mashaly H, Browning AJ, Sundaram SK, Biyani CS. Lesson of the week: lower abdominal pain in women after binge drinking. BMJ 335: 992-993, 2007.

10. Lin AC, Juang GD, Huang CH, Tso CY. An unusual cause of iatrogenic bladder rupture. Am J Emerg Med 24: 512-514, 2006.

11. Saleem MA, Mahmoud AM, Gopinath BR. Spontaneous urinary bladder rupture: a rare differential for lower abdominal pain in a 
female patient. Singapore Med J 50: e410-e411, 2009.

12. Lapointe SP, Pharand D, Lapointe S, Drouin G. Spontaneous rupture of the bladder as a complication of total vaginal prolapse. J Urol 158: 884, 1997.

13. Yeh HC, Ting IW, Huang WY, Huang JW. The case ascites with oliguric acute renal failure. Kidney Int 74: 249-250, 2008.

14. Martens P. Pseudorenal failure secondary to reversed intraperitoneal autodialysis. Case Rep Nephrol 2013: 982391, 2013.

15. Limon O, Unluer EE, Unay FC, Oyar O, Sener A. An unusual cause of death: spontaneous urinary bladder perforation. Am J Emerg Med 30: 2081.e3-2081.e5, 2012.

16. Printza N, Ververi A, Bandouraki M, Vargiami E, Gidaris D, Papachristou F. Life-threatening hyponatremia and acute renal failure due to iatrogenic neonatal bladder rupture. Urol Int 88: 238
$240,2012$.

17. Pintar TJ, Wilke RA. Urinary ascites: spontaneous bladder rupture presenting as acute oliguric renal failure. Am J Med 105: 347-349, 1998.

18. Nguyen-Khac E, Thevenot T, Capron D, et al. Are ascitic electrolytes usable in cirrhotic patients? Correlation of sodium, potassium, chloride, urea, and creatinine concentrations in ascitic and blood. Eur J Intern Med 19: 613-618, 2008.

19. Kelton JG, Ulan R, Stiller C, Holmes E. Comparison of chemical composition of peritoneal fluid and serum: a method for monitoring dialysis patients and a tool for assessing binding to serum proteins in vivo. Ann Intern Med 89: 67-70, 1978.

20. Manery JF. Water and electrolyte metabolism. Physiol Rev 34: 334-417, 1954.

(C) 2015 The Japanese Society of Internal Medicine

http://www.naika.or.jp/imonline/index.html 